\title{
Current Approaches in the Management of Emissional Dysfunction
}

\author{
Kazunori Kihara, Kenji Sato, Masao Ando, Hiroyuki Oshima
}

\begin{abstract}
Abstrak
Tinjauan pustaka ini mengupas mekanisme kontrol syaraf pada traktus seminal dan transpor sperma melalui traktus tersebut, untuk menemukan penanganan rasional dari disfungsi emisional. Makalah ini membahas tentang identifikasi syaraf simpatis retroperitoneal dan intrapelvik yang mengatur pancaran semen dari saluran ejakulatorius (PSSE), jaras kompensatori untuk PSSE sesudah pemotongan syaraf hipogastrika, mekanisme transpor sperma melalui vas deferens, dan cara baru untuk memicu pancaran semen.
\end{abstract}

\begin{abstract}
This revieuw article explored the mechanism of neural control of the seminal tract and sperm transport through it, to approach the rational management of emissional dysfunction. The identification of retroperitoneal and intrapelvic sympathetic nerves controlling seminal emission from the ejaculatory duct (SEED), the compensatory pathways for SEED after transection of hypogastric nerve, the mechanism of sperm transport through the vas deferens, and a new method to generate seminal emission were discussed.
\end{abstract}

Keywords : Seminal emission, ejaculatory duct, lumbar splanchnic nerve, compensatory pathways.

\section{Introduction}

Ejaculation consists of seminal emission, bladder neck closure and protrusion. Seminal emission from the ejaculatory duct (SEED) is regarded to be a spinal reflex that is further modified by the upper central nervous system. Loss of SEED is a cause of infertility in men with spinal cord or other nerve injuries. Stimulating a site of the above reflex arch has been tried to induce artificial seminal emission in such patients, but success has been limited because of serious side effects, low effectiveness, necessity of invasive operation and/or necessity of general anesthesia. To approach the rational management of emissional dysfunction, we explored the mechanisms of neural control of the seminal tract and sperm transport

Department of Urology and Allied Health Science, Tokyo Medical and Dental University, School of Medicine, Tokjo, Japan

Corresponding address :

H. Oshima, M.D., Ph.D.

Department of Urology, Tokyo Medical and Dental University, School of Medicine, 1-5-45, Yushima, Bunkyo-ku, Tokyo 113, Japan through it. The findings lead us to a new method to induce artificial seminal emission.

Identification of retroperitoneal and intrapelvic sympathetic nerves controlling seminal emission from the ejaculatory duct

Seminal emission from the ejaculatory duct (SEED) to the posterior urethra occurs by efferent signals via the retroperitoneal and intrapelvic sympathetic nervous system, and the main signals are regarded to pass through the superior hypogastric plexus and bilateral hypogastric nerves. ${ }^{1-3}$ The proximal pathway to the superior hypogastric plexus has remained controversial; it has been assumed that SEED is controlled by the splanchnic nerves that branch from the lower thoracic and upper lumbar ganglia of the sympathetic trunk but not those from the lower lumbar ganglia. ${ }^{4}$ Our recent study, however, has indicated that not the thoracic splanchnic nerves but each lumba splanchnic nerve $\left(\mathrm{L}_{2-5}\right)$ has the ability to generate SEED as follows. 5

\section{Animals}

The dog was selected as an animal model of SEED. The investigation was started by the study of compara- 
tive anatomy of retroperitoneal sympathetic nervous system between the human and dog. As shown in Figure 1, the retroperitoneal sympathetic nervous system was similar except for the inferior mesenteric and superior hypogastric plexuses in the human, which fuse as the caudal mesenteric plexus in the dog.

\section{Stimulation of the splanchnic nerve}

Operations were carried out under general anesthesia. An exposed nerve was severed and electrical stimulation was given to its distal end using a wire electrode for 5 minutes with stimulus parameters of $8 \mathrm{~V}, 2 \mathrm{msec}$ duration and $10 \mathrm{~Hz}$ provided by a stimulator (Model DPS-06, Daiya Medical System Corp., Tokyo). The experiment of each dog was discontinued once SEED occurred. Seminal emission was observed by exposing verumontanum under vision. Bladder neck contraction was detected with a pressure sensitive balloon catheter inserted into the bladder neck and connected to a pressure transducer (DISA $21 \mathrm{G} 01$ type cystometer). ${ }^{6}$ Electrical stimulation of the intermesenteric plexus which composed of nerve fibers from thoracic and $L_{1}$ ganglia caused emission in none of the dogs examined. In contrast, the same stimulation of each lumba splanchnic nerve branched from the sympathetic trunks below the $\mathrm{L}_{2}$ level generated SEED except for a very few cases (Figure 2 ). ${ }^{5}$ Similar results were obtained for bladder neck closure. ${ }^{6}$ Therefore, it is concluded that efferent signals via the nerves from thoracis and $\mathrm{L}_{1}$ ganglia do not generate seminal emission or bladder neck closure at ejaculation, while those via each lumbar splanchnic nerve $\left(\mathrm{L}_{2-5}\right)$ have ability to generate seminal emission and bladder neck closure.

\section{Control of bilateral seminal emissions from ejaculatory ducts by lumba splanchnic nerve}

Since the presence or absence of SEED by signals through the lumbar splanchnic nerve and the hypogastric nerve has been found as mentioned above, laterality of efferent signals for SEED was investigated. The route of signals for the right and left SEEDs was investigated by electrical stimulation of each lumbar splanchnic nerve in the dog. ${ }^{7}$ The results indicated that each lumba splanchnic nerve generates bilateral SEEDs by sending signals to bilateral epididymal tails and therefore we concluded that some of the signals through each lumbar splanchnic nerve cross to the other side at the caudal mesenteric plexus and/or the prostatic plexus as shown in Figure 3. The contraction pressure of each epididymal tail was measured by inserting a fine elastic needle, which was connected to a transducer (Statham P10EZ, Nihon Kohden Corp., Tokyo), into the vas lumen near the distal end of each epididymal tail. In intact dogs, electrical stimulation of a lumbar splanchnic nerve caused bilateral SEEDs with a greater volume at the stimulated side. After transection of a unilateral hypogastric nerve, bilateral SEEDs occurred by electrical stimulation of the contralateral lumbar splanchnic nerve with a greater volume at the stimulated side and by the stimulation of the ipsilateral lumbar splanchnic nerve with a greater volume at the contralateral side. Stimulation of a lumbar splanchnic nerve caused intraluminal pressures of bilateral epididymal tails regardless of the laterality of hypogastric nerve transection (Figure 4). The pressure increase in the epididymal tail was the greatestat the stimulated side in the presence of an intact ipsilateral hypogastric nerve, which was assumed to be generated by noncrossing signals. The secondary pressure increase in the epididymis occurred by the stimulation of the other side in the presence of an intact ipsilateral hypogastric nerve, indicating the presence of signals crossing to the other side only at the caudal mesenteric plexus. The contraction pressure at the side of a transected hypogastric nerve increased with the weakest level regardless of the side stimulated, indicating the presence of signals crossing to the other side at the site between the hypogastric nerve and the epididymal tail, probably at the prostatic plexus.

\section{Compensatory pathways for SEED after transec- tion of the hypogastric nerve : a mechanism of neurogenic retrograde ejaculation}

Possible sympathetic signals to generate SEED other than those through the lumbar splanchnic nerve and the hypogastric nerve were investigated. Anatomically, two more pathways have been found; one is via the lumbosacral sympathetic trunk and the other via the spermatic nerve. In the presence of intact hypogastric nerves, no SEED except for a trace amount in limited cases occurred by electrical stimulation of the distal end of the lumbosacral sympathetic trunk at the level lower than the branching portion of the lowest lumbar splanchnic nerve and of the spermatic nerves around the spermatic artery. 8,9 One month or more after the transection of bilateral hypogastric nerves, SEED was generated without bladder neck closure by electrical stimulation of each of the above two sympathetic nerves in all dogs examined. Loss of bladder neck closure continued even six months after the transection of bilateral hypogastric nerves. ${ }^{10}$ The results indicate that retrograde ejaculation after bilateral hypogastric 

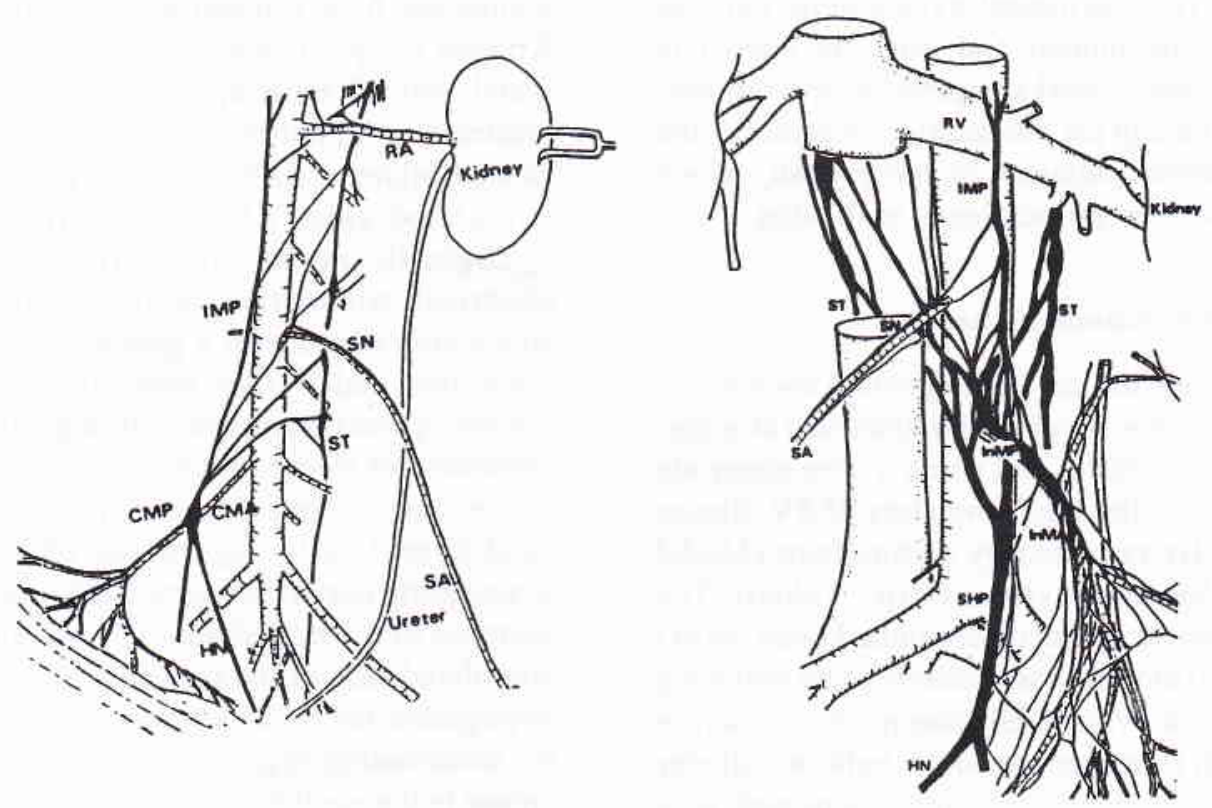

Figure 1. Anatomical dissection of thoracolumbar splanchnic nerves in the dog (left) and human (right). Canine caudal mesenteric plexus coincides with both inferior mesenteric and superior hypogastric plexuses in human. CMA = caudal mesenteric artery, $C M P=$ caudal mesenteric plexus, $H N=$ hypogastric nerve, $I M P=$ intermesenteric plexus, InMP = inferior mesenteric plexus, $I n M A=$ inferior mesenteric artery, $R A=$ renal artery, $R V=$ renal vein, $S A=$ spermatic artery, $S H P=$ superior hypogastric plexus, $S T=$ sympathetic trunk.
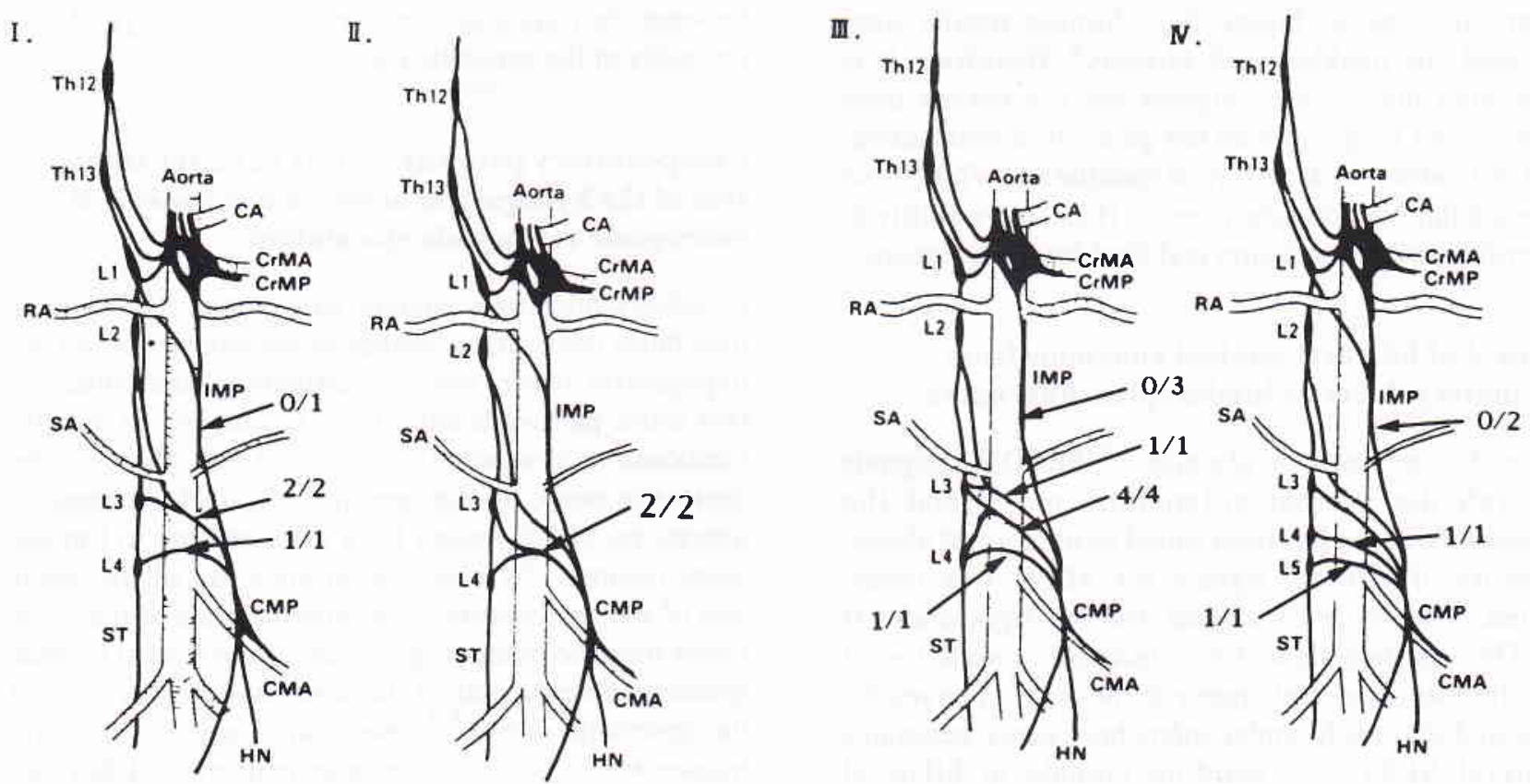

Figure 2. Seminal emission from the ejaculatory duct by electrical stimulation of the splanchnic nerves. Variations of the right lumbar splanchnic nerves and the sites of electrical stimulations were presented. (A) cranial two of three lumbar splanchnic nerves unite to one, (B) cranial two of three lumbar splanchnic nerves unite, $(C)$ three separated and $(D)$ four separated lumbar splanchnic nerves. Cases of seminal emission occurred/number of dogs examined were indicated in the figure. The similar results were obtained in the left side. $C A=$ celiac artery, $C r M P=$ cranial mesenteric plexus, CrMA = cranial mesenteric artery. See legends to Figure 1 for other abbreviations. 

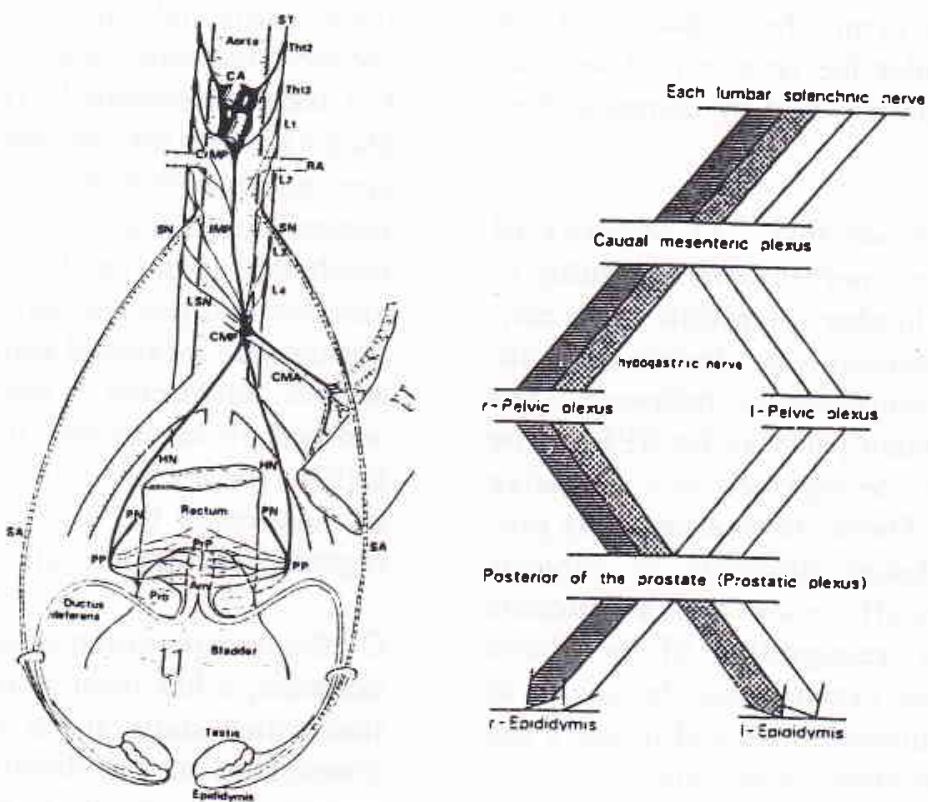

Figure 3. Schematic presentation of canine retroperitoneal and intrapelvic sympath'tic nervous system for seminal emission from the ejaculatory duct (left) and that of 4 groups of signals from each lumbar splanchnic nerve to bilateral vasa deferentia and epididymides (right). Am = ampulla, $L S N=$ lumbar splanchnic nerve, $P N=$ pelvic nerve, $P P=$ pelvic plexus, Pro $=$ prostate, PrP $=$ prostatic plexus, $S N=$ spermatic nerve, $r=$ right, $l=$ left, See legends to Figure l for other abbreviations.
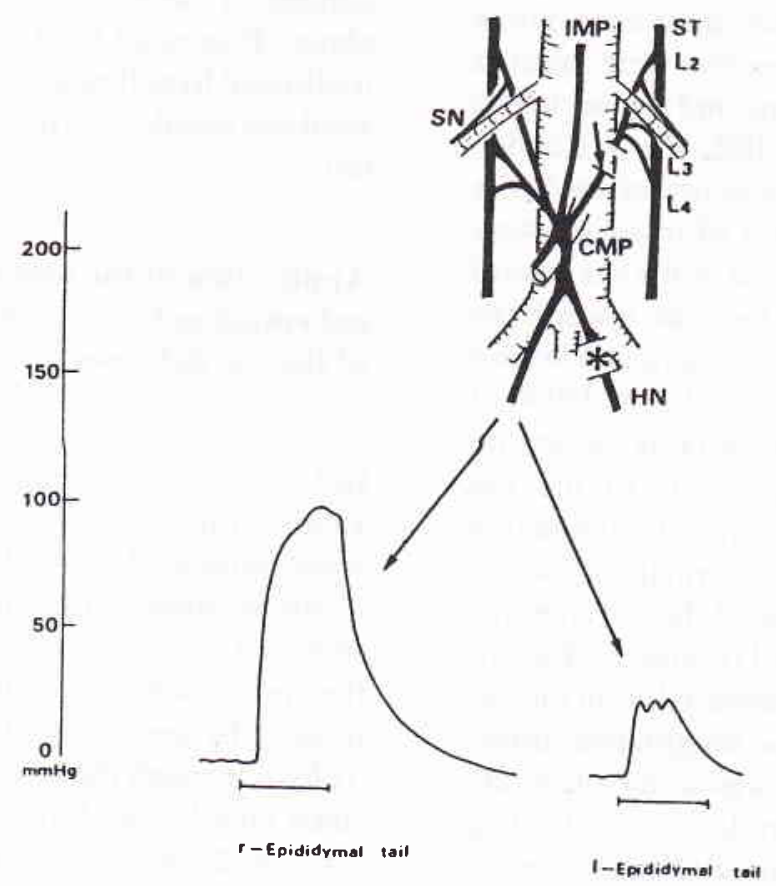

Figure 4. Simultaneously measured contraction pressure profiles of bilateral epididymal tails that were caused by electrical stimulation of a lumbar splanchnic nerve of the same side of the transected hypogastric nerve. The shorr arrow indicates the stimulated site, $r=$ right, $l=$ left. The similar results were observed by electrical stimulation of a lumbar splanchnic nerve of the opposite side of the transected hypogastric nerve. See legends to Figure 1 for abbreviations. 
nerve transections is attributable to the absence of effective compensatory sympathetic pathways for bladder neck closure under the recovery of seminal emission from the ejaculatory duct by compensatory pathways.

The current results indicate that : 1) Majority of bilateral lumbar splanchnic nerves have the ability to generate SEED. 2) Each lumbar splanchnic nerve controls bilateral seminal emissions by double cross-innervation system. 3) Compensatory pathways exist after transection of the main pathway for SEED. The above findings appear to be regarded as a defensive system of reproduction. These observations may provide insight into ejaculatory disorders of subjects with autonomic nerve insufficiency and a rationale for therapy. Surgically, recognition of the above mechanisms and nervous system must be useful to prevent postoperative emission loss and to carry out surgical nerve-sparing to preserve fertility.

\section{Mechanisms a of sperm transport through the vas deferens : introducing new method to generate canine seminal emission}

The mechanism of sperm transport through the vas deferens intraluminal pressure at SEED and mode of transportation of the content in the cauda epididymis were investigated. Three elastic needles were inserted into three sites of the vas deferens and connected to pressure transducers (Statham P10EZ, Nihon Kohden Corp. Tokyo) and intraluminal pressure of each site was simultaneously recorded. Sites of insertion were the distal end of the pars epididymica of the vas toward the epididymis, the middle of the vas toward the epididymis and the proximal end of the ampulla toward the ejaculatory orifice. Direct electrical stimulation of either the testis, epididymal head or body caused no elevation of the intraluminal pressure of the vas deferens and epididymal tail. In contrast, stimulation of any distal sites including the epididymal tail and vas deferens caused marked elevation of the intraluminal pressure only at the epididymal tail (Figure 5). Electrical stimulation of any segments prepared from the vas deferens caused contraction in the longitudinal direction in vitro. This contraction was completely antagonized by the addition of tetrodotoxin, indicating that the muscle contraction by the electrical stimulation to be nerve-transmitted (Figure 6). Stretching the portion of the vas deferens or the epididymal tail by instilling saline into its lumen caused marked elevation of the intraluminal pressure only at the site stretched (Figure 7). A major portion of the dye instilled into the lumen of the epididymal tail was rapidly transported to the ampulla and emitted into the posterior urethra by the electrical stimulation of any site of the epididymal tail and vas deferens. ${ }^{11}$ The above findings appear to shed a light on the mechanism of rapid transport of the spermatozoa stored in the epididymal tail to the posterior urethra as follows. When sympathetic signals reach the epididymal tail, its intraluminal pressure elevates and pushes out spermatozoa to the ampulla through the shortened and straightened vas deferens ${ }^{12}$ and the full stretch of the ampulla by the transport of seminal fluid induces its contraction and leads to SEED. The above results indicate that direct electrical stimulation of the canine vas deferens causes SEED regardless of the site stimulated.

On the transportation of seminal fluid through the vas deferens, it has been generally believed that contraction which starts at the epididymal tail is gradually transmitted to the distal direction and the fluid is transported gradually to the ampulla and emitted into the posterior urethra by the contraction of the ampulla with the greatest amplitude among the vas deferens. ${ }^{13-}$ 15 The current study revealed that direct electrical stimulation of the vas deferens caused emission of the content of the epididymal tail to the posterior urethra regardless of the site stimulated, indicating a new concept of mechanism of sperm transport as described above. If seminal fluid were transported by the above traditional hypothesis, muscle contraction at the stimulated site should interfere the flow from the epididymal tail.

Application of the new method to generate seminal emission to men : direct electrical stimulation of the vas deferens

Before the above method was applied to men, it was validated in dogs whose bilateral hypogastric nerves were transected. Stimulation of any site of the vas deferens caused SEED in all dogs receiving the transection 1, 6 and 12 months before the stimulation. In the application to men, the middle vas was stimulated directly by penetrating two Pole needles (TOP Corp., Tokyo) through the scrotal skin to the manually stabilized middle vas. Stimulus parameters for men were $15-20 \mathrm{~V}, 2 \mathrm{msec}$ and $10 \mathrm{~Hz}$. for 5 minutes. All stimulations of patients with emission loss generated SEED, although pressing of the ampulla was necessary for each case examined. The motility rate was low in all ejaculates obtained from those with old spinal cord injury. No major side effects were observed except for 
Sites measured

\begin{tabular}{lll}
\multicolumn{3}{c}{ Sites stimulated } \\
$T, E$ & $C E$ & $M V$
\end{tabular}

Ampulla

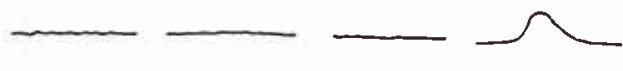

Middle

vas

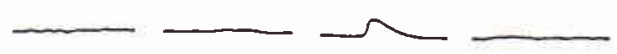

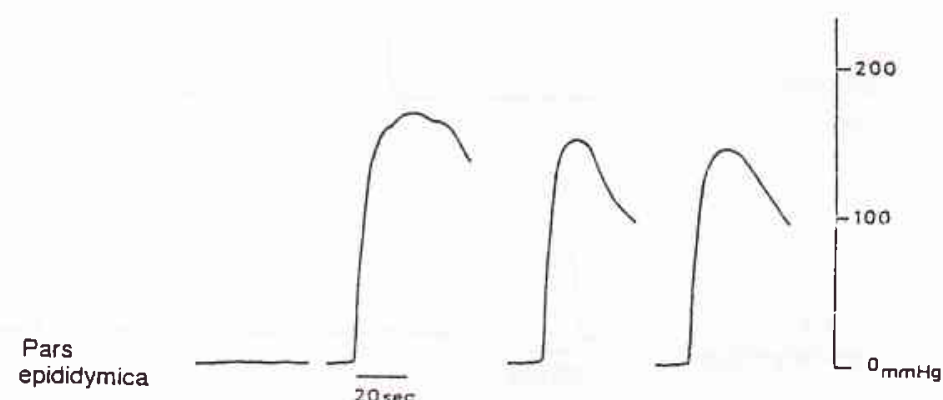

Figure 5. Intraluminal pressure of the epididymis and vas deferens by direct electrical stimulation (2msec, $8 \mathrm{~V}, 10 \mathrm{~Hz}$; nerve stimulation) of the seminal tract. $T=$ testis, $E=$ head and body of the epididymis, $E T=$ epididymal tail, $M V=$ middle vas, Am = ampulla.

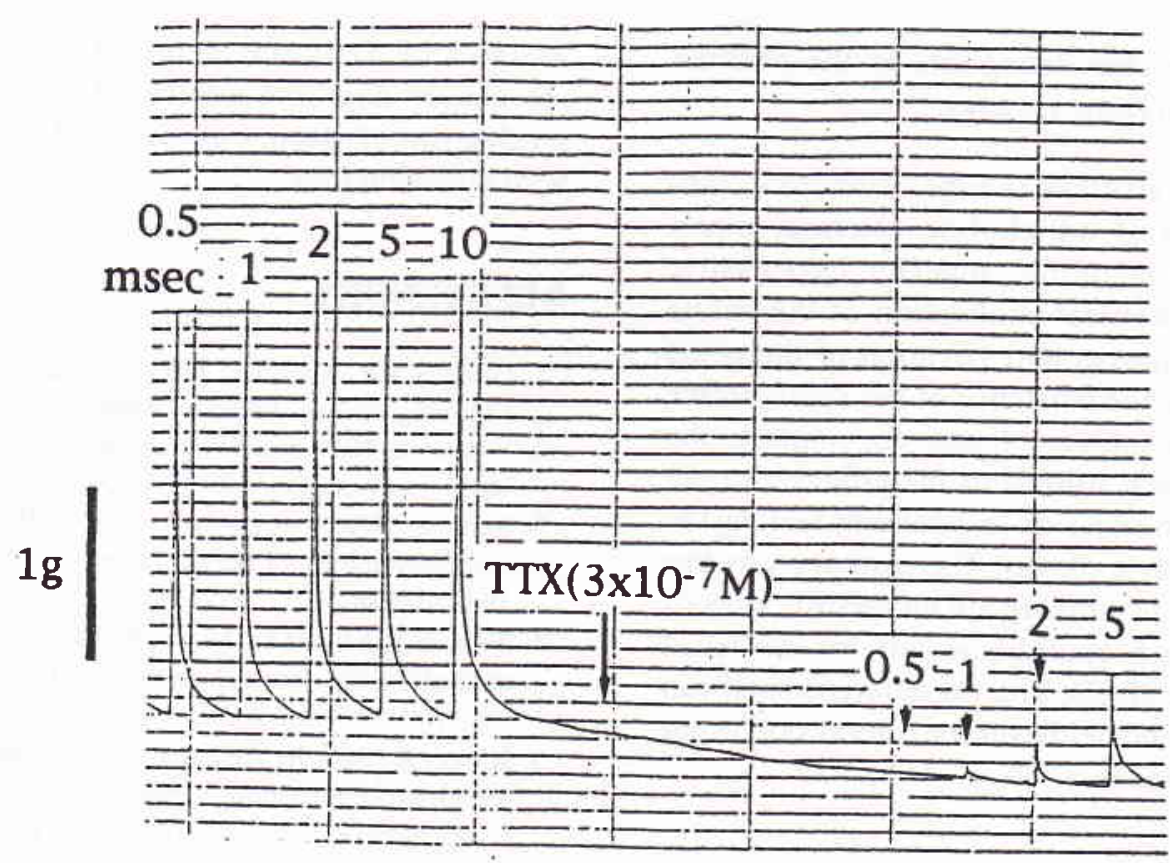

\section{$10 \mathrm{~min}$}

Figure 6. Inhibition of muscle contraction of the ampulla of the canine vas deferens by tetrodotoxin (TTX). Stimulus parameters for electrical stimulation of the vas were $0.5-5 \mathrm{msec}, 80 \mathrm{~V}$ and $20 \mathrm{~Hz}$ for 5 second. The arrow indicates addition of tetrodotoxin at the concentration of $3 \times 10^{-7} \mathrm{M}$. 
Sites measured

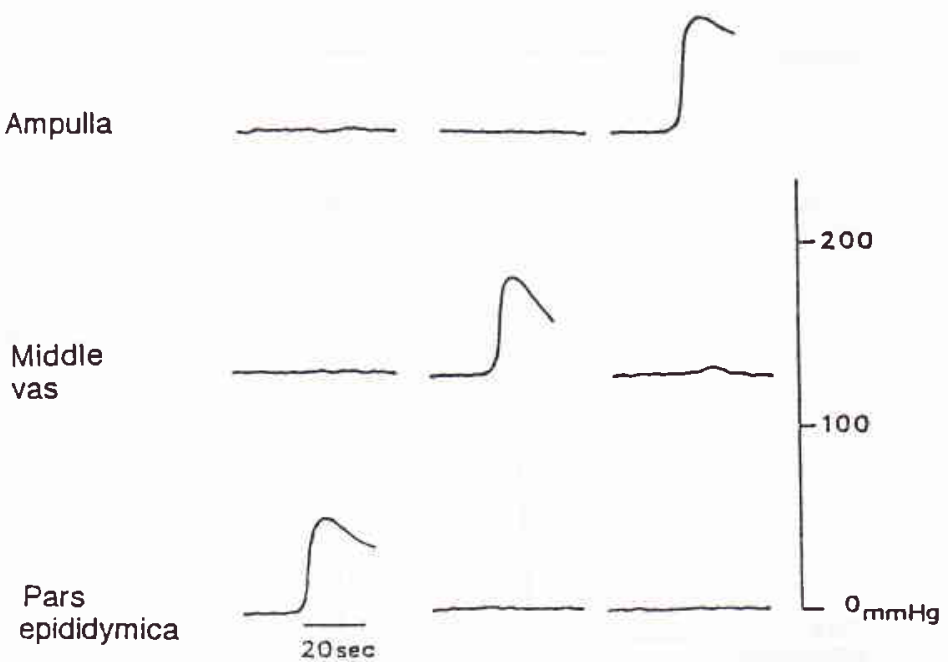

Figure 7. Intraluminal pressure of the epididymis and vas deferens by stretching the wall of the duct by instilling saline into the lumen. $P E=$ pars epidid'mica of the vas, $M V=$ middle vas, $A M=$ ampulla.

a slight pain at the stimulating site at the scrotum during stimulating in some patients. ${ }^{11}$

Previous trials for artifical seminal emission; subarachnoid injection of anticholine esterase, direct electrical stimulation of the superior hypogastric nerve, transrectal electrical stimulation of the pelvic plexus or prostatic plexus and vibration of the penis have depended upon the existence of the spinal reflex arch or at least the pelvic plexus. In contrast, the present method, which stimulates the effective organ itself, is applicable to emission loss patients lacking the reflex arch or the pelvic plexus. The current study has further demonstrated that there are no specific sites of the vas deferens and epididymal tail for electrical stimulation to cause SEED. The vas deferens itself can be easily identified and held over the scrotal skin using the fingers to stabilize it.

\section{CONCLUSION}

The current studies showed the elaborate mechanisms of the retroperitoneal and intrapelvic sympathetic nervous system to preserve SEED against various injuries of the peripheral sympathetic nervous system and introduced such an easy, safe and repeatable method of artificial seminal emission from the ejaculatory duct that was based on a new concept of mechanism of sperm transport and applicable to those with emission loss.

\section{REFERENCES}

1. Langley JM, Anderson HK. Innervation of the pelvic and adjoining viscera. J Physiol 1896;19:372-84.

2. Leamonth JR. Contribution to neurophysiology of urinary bladder in man. Brain 1931;45:147-76.

3. Semans JH, Langworthy OR. Observation on the neurophysiology of sexual function in the male cat. J Urol 1938;40:836-46.

4. Kimura Y, Miyata K, Adachi K, Kisaki N. Peripheral nerves controlling the internal urethral orifice during ejaculation. Urol Int 1975;30:218-27.

5. Kihara K, Sato K, Ando M, Sato T, Oshima H. Ability of each lumbar splanchnic nerve and disability of thoracic ones to generate seminal emission in the dog. J Urol $1992 ; 147: 260-3$.

6. Ando M, Kihara K, Sato K, Sato T, Oslima H. Regulation of the bladder neck closure by lumbar splanchnic nerves at ejaculation in the dog. Neurourol Urodynam 1993;12:91-8.

7. Kihara K, Sato K, Ando M, Morita T, Oshima H. Control of bilateral seminal emissions from ejaculatory ducts by a lumbar splanchnic nerve. Am J Physiol 1993;265:R743-8. 
8. Kihara K, Sato K, Ando M, Sato T, Oshima H. Lumbosacral sympathetic trunk as a compensatory pathway for seminal emission after bilateral hypogastric nerve transections in the dog. J Urol 1991;145:640-3.

9. Sato K, Kihara K, Ando M, Sato T, Oshima H. Semina] emission by electrical stimulation of the spermatic nerve and epididymis. Int J Androl 1991;14:461-7.

10. Kihara K, Sato K, Ando M, Sato S, Oshima H. A mechanism of retrograde ejaculation after bilateral hypogastric nerve transections in the dog. J Urol 1992;148:1307-9.

11. Kihara K, Sato K, Ando M, Ushiyama T, Azuma H, Oshima H. A new method to generate canine seminal emission and its application to men : Direct electrical stimulation of the vas deferens. J Androl in press.
12. Mitsuya H, Asai J, Ushida T, Hosoe K. Application of X-ray cinematography in urology : Mechanism of ejaculation. $\mathrm{J}$ Urol 1960;83:86-92.

13. Baumgarten HG, Holstein AF, Rosengren E. Arrangement, ultrastructure and adrenergic innervation of smooth musculature of the ductuli efferentes, ductus epididymidis and ductus deferens of man. Z Zellforch. 1971;120:37-79.

14. Narita $H$. The study of sperm transport through the human genital tract. Jpn J Urol 74:1735-48.

15. Ventura WP, Freund M, Davis J, Pannuti C. Influence of norepinephrine on the motility of the human vas deferens : A new hypothesis of sperm transport by the vas deferens. Fertil Steril 1973;24:68-77. 